
p.76-80, jan.-mar. 2005 .

\title{
Doses de nitrogênio na produção de couve-da-Malásia
}

\author{
Luiz Antônio Zanão Júnior ${ }^{1}$; Regina Maria Q. Lana ${ }^{1}$; Marli A. Ranal ${ }^{2}$
}

UFU, 'Instituto de Ciências Agrárias, ${ }^{2}$ Instituto de Biologia, C. Postal 593, 38400-902 Uberlândia-MG; E-mail: luizantoniozanao@agro.ufu.br

\begin{abstract}
RESUMO
É recomendável que a introdução de uma cultura em uma região passe por avaliações prévias que demonstrem a produtividade das plantas nas condições edafo-climáticas do local, bem como suas exigências nutricionais. Isto vem sendo feito com Brassica chinensis var. parachinensis, introduzida no Brasil, município de Uberlândia, em 1992. Avaliou-se o efeito de doses de nitrogênio na produtividade e na acumulação de nutrientes na parte aérea das plantas, em experimento em delineamento de blocos casualizados, com cinco tratamentos incluindo quatro doses de N $\left(105 ; 210 ; 315\right.$ e $\left.420 \mathrm{~kg} \mathrm{ha}^{-1}\right)$ e a testemunha sem $\mathrm{N}$, e quatro repetições. O nitrogênio foi aplicado parceladamente, sendo $30 \%$ da respectiva dose na semeadura, $35 \%$ aos 15 e $35 \%$ aos 30 dias após a semeadura. Foram avaliados massa fresca e seca da parte aérea e das raízes, número de folhas, diâmetro do caule e acumulação de $\mathrm{N}, \mathrm{P}, \mathrm{K}, \mathrm{Ca}, \mathrm{Mg}, \mathrm{S}, \mathrm{B}, \mathrm{Cu}, \mathrm{Fe}, \mathrm{Mn}$ e Zn pela parte aérea de plantas cultivadas em casa de vegetação, em vasos de $5 \mathrm{dm}^{3}$ contendo Latossolo Vermelho Distrófico típico. A couve-da-Malásia respondeu significativamente à aplicação de nitrogênio, sendo o maior crescimento, a maior produtividade e absorção de nutrientes registrados na dose de $210 \mathrm{~kg} \mathrm{ha}^{-1}$, exceto o N, Mn e $\mathrm{Zn}$ que aumentaram linearmente.
\end{abstract}

Palavras-chave: Brassica chinensis L. var. parachinensis (Bailey) Sinskaja, "tsoi sum", adubação nitrogenada.

\begin{abstract}
Nitrogen doses in the flowering white cabbage yield

It is recommendable that the introduction of a new culture in a region be previously evaluated in the yield and nutrition aspects under local soil and climatic conditions. Thus, since 1992 when Brassica chinensis L. var. parachinensis was introduced in Brazil, this variety has been studied by Brazilian researchers. The experiment was conduced in a greenhouse, in randomized blocks, with five treatments and four replicates, including four doses of nitrogen $(105 ; 210 ; 315$ and $420 \mathrm{~kg} \mathrm{ha}^{-1}$ ) and the control treatment to evalute the effect of nitrogen doses on the yield and the accumulation of nutrients by plants of this variety. Plants were planted in pots of $5 \mathrm{dm}^{3}$ containing a Red Latosol dystrophic soil. The nitrogen was applied three times, when sowing (30\%), at 15 and at 30 days after sowing $(35+35 \%)$. Fresh and dry mass of the aerial part and roots of the plants, number of leaves, stem diameter, and the accumulation of N, P, K, Ca, Mg, $\mathrm{S}, \mathrm{B}, \mathrm{Cu}, \mathrm{Fe}, \mathrm{Mn}$, and $\mathrm{Zn}$ by aerial part of the plants were evaluated. The best dose of nitrogen was $210 \mathrm{~kg} \mathrm{ha}^{-1}$, where the highest yield and nutrient absorption were registered, except $\mathrm{N}, \mathrm{Mn}$, and $\mathrm{Zn}$ that increased linearly.
\end{abstract}

Keywords: Brassica chinensis L. var. parachinensis (Bailey) Sinskaja, "tsoi sum", nitrogen fertilization.

\section{(Recebido para publicação em 18 de fevereiro de 2004 e aceito em 16 de novembro de 2004)}

$B$ rassica chinensis L. var. parachinensis (Bailey) Sinskaja (Bailey, 1930) é uma das mais saborosas couves chinesas (Herklots, 1972); não forma cabeça (Opeña et al., 1988), é de ciclo curto (Lee, 1982; Ferreira et al., 2002) e própria para o consumo de folhas, flores e caules (Herklots, 1972). Nativa da China, tem sido extensivamente cultivada no sudeste asiático e Austrália (Bailey, 1930; Herklots, 1972; Lee, 1982; Hill, 1990). Segundo Opeña et al. (1988), sua popularidade tem aumentado entre os povos não orientais nos últimos anos, sendo conhecida como "mock pak-choi" (Bailey, 1930), "flowering white cabbage", "paak ts'oi sum" (Herklots, 1972; Opeña et al., 1988), "tsoi sum” (Opeña et al., 1988; Hill, 1990) e couve-da-Malásia, denominação esta adotada no Brasil por Warwick E. Kerr que a introduziu no País em 1992, a partir de sementes trazidas da Malásia, em função do seu alto teor de vitamina A.
As couves chinesas têm se destacado na alimentação humana por influência desse povo, cujo consumo é de 500 g por pessoa, por dia, consumo este muito maior do que o registrado nos EUA e Europa (Lee, 1982). Na China, em 1974-75, a produção dessa couve foi equivalente a $23 \%(=95215 \mathrm{t})$ do total de vegetais produzidos, sendo ainda necessária a importação de mais $8 \%$, o que mostra que naquele país esta variedade é comercialmente atrativa em função da alta demanda (Yip et al., 1976).

Em 1992 foram feitos os primeiros experimentos com a variedade no município de Uberlândia. Em setembro desse ano, sementes produzidas no município apresentaram alta germinabilidade em condições de laboratório $(99,6 \%)$, tanto na luz como no escuro (Ferreira e Ranal, 1999). Em condições de campo suas plântulas emergiram entre dois e três dias, de 0,5 a 1,5 $\mathrm{cm}$ de profundidade, alcançando $96 \%$ de emergência (Ferreira e Ranal, 1999).
No cultivo de março a junho de 1993, alcançou a maior produtividade agronômica em espaçamento $30 \times 10 \mathrm{~cm}$, com adubação mineral (30 $\mathrm{kg} \mathrm{ha}^{-1}$ de nitrogênio no preparo do solo e $40 \mathrm{~kg} \mathrm{ha}^{-1}$ em cobertura, ambos aplicados como sulfato de amônio), sendo estimadas $21,5 \mathrm{t} \mathrm{ha}^{-1}$ (Ferreira et al., 2002), valor este incluído na faixa registrada para a China (16,3 a 28,8 $\mathrm{t} \mathrm{ha}^{-1}$, Yip et al., 1976) e Malásia (11 a $20 \mathrm{t} \mathrm{ha}^{-1}$, Idris e Abidin, 1987, citados por Hill, 1990). Na China, a maior produtividade foi alcançada em espaçamento $10 \times 10 \mathrm{~cm}$, com aplicação de 45, 90 e $135 \mathrm{~kg} \mathrm{ha}^{-1}$ de nitrogênio como sulfato de amônio (Yip et al., 1976). Na Austrália, a maior produtividade $\left(46,1 \mathrm{t} \mathrm{ha}^{-1}\right)$ também foi alcançada em cultivo adensado ( $10 \times 10$ $\mathrm{cm}), \operatorname{com} 200 \mathrm{~kg} \mathrm{ha}^{-1}$ de nitrogênio como nitrato de amônio, sendo que em espaçamentos maiores, 30 x 30 e 20 x $20 \mathrm{~cm}$, as produtividades máximas foram de aproximadamente $6 \mathrm{e} 19 \mathrm{t} \mathrm{ha}^{-1}$ respectivamente, com $100 \mathrm{~kg} \mathrm{ha}^{-1}$ de 
nitrogênio (Hill, 1990). Segundo Trani et al. (1994), dentre as hortaliças, as brássicas apresentam grande capacidade de resposta a esse nutriente, verificando-se aumentos na produtividade com aplicações crescentes de N, até 300 $\mathrm{kg} \mathrm{ha}{ }^{-1}$.

No Brasil, pouco se conhece sobre as exigências nutricionais dessa variedade, sendo as recomendações de adubação para seu cultivo feitas, até o momento, com base nas recomendações para hortaliças folhosas como a alface. Sabe-se que plantas dessa variedade são altamente sensíveis à falta de nitrogênio, fósforo, potássio, enxofre (Sousa, 1997) e boro (Mota, 2001).

Para dar suporte teórico à produção brasileira dessa variedade em escala comercial, o presente trabalho teve por objetivo avaliar a resposta da cultura a diferentes doses de nitrogênio.

\section{MATERIAL E MÉTODOS}

O experimento foi conduzido em casa de vegetação, em vasos de $5 \mathrm{dm}^{3}$, mantidos em espaçamento de $20 \times 20$ $\mathrm{cm}$, em área da UFU. A temperatura média das mínimas na casa de vegetação, durante o período em que o experimento foi conduzido, foi de $21,3^{\circ} \mathrm{C}$ e a média das máximas de $29,2^{\circ} \mathrm{C}$.

Utilizou-se solo da camada superficial (0 a $20 \mathrm{~cm}$ ) de um Latossolo Vermelho Distrófico típico, textura média, com pH H $\mathrm{H}_{2} \mathrm{O}(1: 2,5)=5,2$; $\mathrm{P}($ Mehlich-1) $=$ $16,5 \mathrm{mg} \mathrm{dm}^{-3} ; \mathrm{K}^{+}$(Mehlich-1) $=37,8 \mathrm{mg}$ $\mathrm{dm}^{-3} ; \mathrm{Al}^{+3}, \mathrm{Ca}^{+2}, \mathrm{Mg}^{+2}, \mathrm{H}+\mathrm{Al}=0,2 ; 0,6$; 0,1 e $3,2 \mathrm{cmol}_{\mathrm{c}} \mathrm{dm}^{-3}$, respectivamente; saturação por bases $=19 \%$, matéria orgânica $=1,4$ dag $\mathrm{kg}^{-1} ; \mathrm{B}, \mathrm{Cu}, \mathrm{Fe}, \mathrm{Mn}, \mathrm{Zn}$ e $\mathrm{S}_{-} \mathrm{SO}_{4}^{-2}=0,24 ; 0,7 ; 55 ; 9,1$ e $6,0 \mathrm{mg}$ $\mathrm{dm}^{-3}$, respectivamente. A análise do solo foi feita segundo metodologia descrita por Silva et al. (1999).

Foram avaliados o tratamento controle (solo sem adição de nitrogênio) e quatro doses de nitrogênio $(105 ; 210$; 315 e $420 \mathrm{~kg} \mathrm{ha}^{-1}$ ), em delineamento de blocos casualizados, com quatro repetições. O preparo do solo foi feito para cada vaso. A calagem foi realizada para elevar a saturação por bases a $70 \%$, conforme recomendação feita por Ribeiro et al. (1999) para a cultura da alface, aplicando-se 2,0 $\mathrm{t} \mathrm{ha}^{-1} \mathrm{de}$ calcário dolomítico calcinado (PRNT $100 \%$ ). O solo dos vasos foi incubado por 30 dias.

A semeadura foi realizada no dia 03 / 01/2003, a $1 \mathrm{~cm}$ de profundidade, com cinco sementes por vaso. Após a emergência, realizou-se o desbaste, deixando-se uma planta por vaso, a mais vigorosa e centralizada. A irrigação foi feita duas vezes ao dia, colocando-se $100 \mathrm{ml}$ de água por vaso em cada período. $\mathrm{Na}$ semeadura, foram aplicados $400 \mathrm{~kg} \mathrm{ha}^{-1}$ de $\mathrm{P}_{2} \mathrm{O}_{5}$ e $60 \mathrm{~kg} \mathrm{ha}^{-1}$ de $\mathrm{K}_{2} \mathrm{O}$. As doses também seguiram as recomendações feitas para a cultura da alface (Ribeiro et al., 1999). Como a couve-da-Malásia é muito responsiva à aplicação de boro (Mota, 2001), aplicou-se $1 \mathrm{~kg} \mathrm{ha}^{-1}$ deste micronutriente, na forma de bórax. Os fertilizantes foram aplicados misturados ao solo dos vasos no momento da semeadura. A quantidade de nitrogênio foi parcelada em três épocas, sendo aplicados $30 \%$ da dose total na semeadura, juntamente com os demais fertilizantes, $35 \%$ aos 15 e aos 30 dias após a semeadura, ambas em cobertura. Em cada cobertura com nitrogênio, aplicou-se também $50 \mathrm{~kg} \mathrm{ha}^{-1}$ de $\mathrm{K}_{2} \mathrm{O}$, totalizando 160 $\mathrm{kg} \mathrm{ha}^{-1}$. O sulfato de amônio foi empregado como fonte de $\mathrm{N}$, o superfosfato triplo como fonte de $\mathrm{P}_{2} \mathrm{O}_{5}$ e como fonte de $\mathrm{K}_{2} \mathrm{O}$ o cloreto de potássio.

A colheita foi realizada 45 dias após a semeadura, para avaliação da massa fresca da parte aérea (MFPA), massa seca da parte aérea (MSPA), número de folhas (NF), massa fresca de raízes (MFR), massa seca de raízes (MSR), diâmetro do caule (DC), teores e acumulação dos macronutrientes $(\mathrm{N}, \mathrm{P}, \mathrm{K}$, $\mathrm{Ca}, \mathrm{Mg}$ e $\mathrm{S})$ e micronutrientes $(\mathrm{B}, \mathrm{Cu}$, $\mathrm{Fe}, \mathrm{Mn}$ e $\mathrm{Zn}$ ) pela parte aérea das plantas. O número de folhas foi obtido fazendo-se a contagem das mesmas no momento da avaliação da massa fresca da parte aérea.

As plantas foram retiradas com o solo aderido às suas raízes, de modo a não danificá-las e ocorrer perda de parte do sistema radicular. Posteriormente, o sistema radicular foi separado da parte aérea. As raízes foram lavadas cuidadosamente até a retirada do solo aderido às mesmas. $\mathrm{O}$ excesso de água foi retirado com o auxílio de papel toalha e em seguida o material foi avaliado quan- to à massa. O diâmetro do caule foi medido com o auxílio de um paquímetro. As matérias secas da parte aérea e de raízes foram obtidas secando-se as respectivas partes em estufa de circulação forçada de ar a $70^{\circ} \mathrm{C}$, até massa constante. A análise química da parte aérea das plantas, para determinação do teor de macronutrientes e micronutrientes, foi feita com base na metodologia recomendada por Bataglia et al. (1985).

$\mathrm{O}$ acúmulo de macronutrientes e micronutrientes ( $\mu$ g planta ${ }^{-1}$ e m planta ${ }^{-1}$, respectivamente) foi obtido pelo produto entre a massa da matéria seca e o teor destes nutrientes na parte aérea das plantas ( $\mathrm{g} \mathrm{kg}^{-1}$ e $\mathrm{mg} \mathrm{kg}^{-1}$, respectivamente).

Os dados obtidos foram inicialmente submetidos aos testes de normalidade (Shapiro-Wilk) e homogeneidade (Levene), para se determinar, caso necessário, a transformação a ser adotada. Como as variâncias foram homogêneas entre os tratamentos e os resíduos da análise da variância apresentaram distribuição normal, nenhum deles foi transformado. O teste $F$ a $5 \%$ de probabilidade foi utilizado para avaliar a significância das equações polinomiais, referentes aos efeitos das doses de nitrogênio aplicadas.

\section{RESULTADOS E DISCUSSÃO}

A análise de regressão mostrou efeito significativo $(\mathrm{P} \leq 0,05)$ das doses de nitrogênio aplicadas, sobre a massa fresca e seca da parte aérea e raízes, número de folhas por planta, diâmetro do caule, acumulação de macronutrientes e de micronutrientes pela parte aérea, exceto boro. Observou-se resposta quadrática para massa fresca e seca da parte aérea e das raízes e para número de folhas por planta (Tabela 1), bem como para a acumulação de $\mathrm{P}, \mathrm{K}, \mathrm{Ca}, \mathrm{Mg}, \mathrm{S}, \mathrm{Fe}$ e $\mathrm{Cu}$ (Figuras 1 e 2), e resposta linear para diâmetro de caule (Tabela 1) e acumulação de N, Mn e Zn pela parte aérea (Figuras 1 e 2).

Aos 45 dias após a emergência, a dose intermediária de nitrogênio $(210 \mathrm{~kg}$ $\left.\mathrm{ha}^{-1}\right)$, comparativamente à testemunha, propiciou o maior acúmulo dos macronutrientes pela parte aérea das plantas, exceto nitrogênio (Figura 1). 
Tabela 1. Massa fresca da parte aérea (MFPA), massa seca da parte aérea (MSPA), massa fresca de raízes (MFR), massa seca de raízes (MSR), diâmetro do caule (DC) e número de folhas por planta (NF) da couve-da-Malásia, em função de diferentes doses de nitrogênio. Uberlândia, UFU, 2003.

\begin{tabular}{|c|c|c|c|c|c|c|}
\hline$N\left(k h^{-1}\right)$ & $\begin{array}{c}\text { MFPA } \\
\left(\text { g planta-1) }^{-1}\right.\end{array}$ & $\begin{array}{c}\text { MSPA } \\
\text { (g planta-1) }^{-1}\end{array}$ & $\begin{array}{c}\text { MFR } \\
\text { (g planta-1) }\end{array}$ & $\begin{array}{c}\text { MSR } \\
\left(\text { g planta-1) }^{-1}\right)\end{array}$ & $\begin{array}{c}\text { DC } \\
(\mathrm{mm})\end{array}$ & NF \\
\hline 0 & 41,34 & 6,95 & 4,27 & 0,495 & 9,05 & 9,75 \\
\hline 105 & 89,97 & 9,71 & 5,99 & 1,077 & 16,58 & 14,00 \\
\hline 210 & 114,55 & 13,01 & 8,42 & 1,277 & 17,20 & 17,50 \\
\hline 315 & 112,63 & 12,39 & 6,86 & 0,853 & 18,00 & 14,50 \\
\hline 420 & 111,40 & 12,00 & 6,02 & 0,780 & 19,79 & 13,90 \\
\hline
\end{tabular}

\begin{tabular}{lcccccc}
\hline $\begin{array}{l}\text { Ajuste da } \\
\text { regressão }\end{array}$ & $\mathrm{Q}^{*}$ & $\mathrm{Q}^{*}$ & $\mathrm{Q}^{*}$ & $\mathrm{Q}^{*}$ & $\mathrm{~L}^{*}$ & $\mathrm{Q}^{*}$ \\
\hline $\mathrm{R} 2$ & 0,98 & 0,96 & 0,76 & 0,85 & 0,75 & 0,79 \\
\hline $\mathrm{CV}(\%)$ & 13,6 & 12,7 & 14,5 & 4,7 & 7,6 & 16,2 \\
\hline
\end{tabular}

* Ajuste significativo a $5 \%$ de probabilidade pelo teste $F ; Q$ : ajuste quadrático; $L$ : ajuste linear; $C V$ : coeficiente de variação.

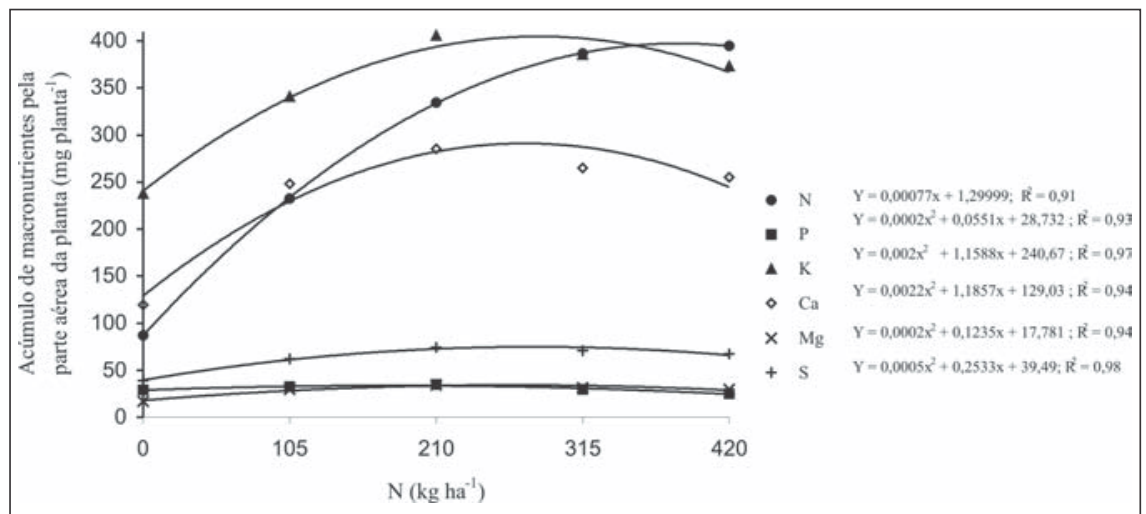

Figura 1. Acúmulo de macronutrientes (N, P, K, Ca, Mg e S) pela parte aérea da couve-daMalásia, em função de doses de nitrogênio. Uberlândia, UFU, 2003.

Com esta dose, a ordem de acumulação de macronutrientes foi $\mathrm{K}>\mathrm{N}>\mathrm{Ca}>\mathrm{S}>\mathrm{P}>\mathrm{Mg}$. Sousa (1997), estudando o efeito de macronutrientes na produtividade da couve-da-Malásia, verificou que esta foi bastante reduzida em plantas cultivadas na ausência de N, P, S e K. Segundo Furlani et al. (1978), as brássicas são mais responsivas ao $\mathrm{N}$ e $\mathrm{P}$, mas são também exigentes em $\mathrm{Ca}$ e $\mathrm{S}$ e retiram do solo maiores quantidades de $\mathrm{K}$ e $\mathrm{N}$. Segundo os autores, o nitrogênio favorece o acúmulo de nutrientes porque aumenta a produção de biomassa, estimulando o crescimento vegetativo e de raízes, o que resulta em maior absorção destes. Neste experimento, observou-se que o nitrogênio aumentou a acumulação dos demais nutrientes, até a dose de $210 \mathrm{~kg} \mathrm{ha}^{-1}$.

Em solo não adubado com nitrogênio, as plantas apresentaram sintomas visuais de deficiência semelhantes aos descritos por Sousa (1997), quando esta brássica foi cultivada em solução nutritiva com omissão deste nutriente, como raquitismo das plantas, redução da área foliar e tonalidade verde-claro das folhas. O menor crescimento das plantas desse tratamento pode ser comprovado pelos dados apresentados na Tabela 1 . Ao contrário, na dose de $420 \mathrm{~kg} \mathrm{ha}^{-1}$ de $\mathrm{N}$, as folhas adquiriram tom verde mais escuro, o que pode estar evidenciando sintomas de toxicidez por excesso deste elemento.

A acumulação linear de zinco e manganês pode estar relacionada à maior absorção e translocação destes nutrientes, em relação aos demais, provavelmente devido à adubação nitrogenada, que pode causar acidificação da rizosfera, provocada pela nitrificação ou pela absorção do íon amônio. A acidificação da rizosfera, segundo Moraghan e Mascagni (1991), aumenta a eficiência na absorção de micronutrientes metálicos.

A ordem de acumulação de micronutrientes, quando da utilização da melhor dose de nitrogênio, foi $\mathrm{Fe}>\mathrm{Mn}>\mathrm{Zn}>\mathrm{B}>\mathrm{Cu}$ (Figura 2). Este último geralmente é encontrado em quantidades muito baixas no solo e na matéria seca das plantas (Ferreira e Cruz, 1991). Segundo Castellane et al. (1991), esta é a ordem de acumulação de micronutrientes pelas plantas olerícolas em geral. No entanto, Mota (2001) registrou para esta mesma variedade, maior absorção de boro e depois do zinco. Para os demais micronutrientes, a ordem registrada pelo autor foi a mesma.

Pode-se estimar que com $210 \mathrm{~kg} \mathrm{ha}^{-1}$ de N, uma população de 333.333 plantas de couve-da-Malásia por hectare é capaz de remover do solo, em $\mathrm{kg} \mathrm{ha}^{-1}$, 112,34 de N; 11,9 de P; 134,8 de K; 94,8 de $\mathrm{Ca} ; 11,4$ de $\mathrm{Mg}$ e 24,8 de $\mathrm{S}$ e em g ha $^{-1}, 440$ de B; 160 de $\mathrm{Cu} ; 4700$ de Fe; 9400 de Mn e 1900 de Zn. Essas estimativas são muito superiores às calculadas para a couve-flor (Kimoto, 1993), o que confirma a alta capacidade de extração de nutrientes do solo pelas brássicas.

Os teores de N, Fe e Zn na parte aérea da couve-da-Malásia aumentaram com o aumento das doses de $\mathrm{N}$ e os teores dos demais nutrientes diminuíram a partir da dose de $105 \mathrm{~kg} \mathrm{ha}^{-1}$ (Tabela 2). A diminuição do teor destes nutrientes pode estar relacionada com o aumento da matéria seca da parte aérea que, na nutrição de plantas, se denomina efeito de diluição.

As produções de massa fresca e seca da parte aérea foram semelhantes para as doses de 210; 315 e $420 \mathrm{~kg} \mathrm{ha}^{-1} \mathrm{de} \mathrm{N}$ (Tabela 1). Isto é explicado pelo fato de que o número de folhas alcançado com $210 \mathrm{~kg} \mathrm{ha}^{-1} \mathrm{de} \mathrm{N}$ foi superior às demais doses. No entanto, o diâmetro do caule alcançado com 315 e $420 \mathrm{~kg} \mathrm{ha}^{-1}$ de $\mathrm{N}$ foi superior aos demais tratamentos, $\mathrm{o}$ que conferiu às plantas massas equivalentes nestas três doses.

A produção de massa fresca da parte aérea (produtividade agronômica) alcançada neste experimento com as três maiores doses de nitrogênio foi superior à máxima produção obtida por Ferreira et al. (2002), quando estudaram 
a mesma variedade em Uberlândia, em condições de campo, com adubação orgânica e mineral em diferentes espaçamentos (93 g planta $^{-1}$ ), utilizando $70 \mathrm{~kg} \mathrm{ha}^{-1}$ de $\mathrm{N}$ e por Dantas (1997), com aplicação de metanol e $80 \mathrm{~kg} \mathrm{ha}^{-1}$ de $\mathrm{N}$ em vasos mantidos em casa de vegetação (52 $\left.\mathrm{g} \mathrm{planta}^{-1}\right)$. A produção registrada no presente trabalho também foi superior à obtida por Hill (1990), em espaçamento 10 x $10 \mathrm{~cm}$, com aplicação de $200 \mathrm{~kg} \mathrm{ha}^{-1}$ de N (46 g planta $\left.\mathrm{g}^{-1}\right)$, em cultivo realizado em campo na Austrália. Esses resultados mostram que o nitrogênio é fator limitante para a produtividade agronômica dessa variedade.

O maior valor de massa seca de raízes foi registrado para a dose de 210 $\mathrm{kg} \mathrm{ha}^{-1}$ de $\mathrm{N}\left(1,28 \mathrm{~g}_{\text {planta-1 }}\right)$. Esta produção foi inferior à obtida por Sousa (1997) e superior à encontrada por Mota (2001), que foram de 2,84 $\mathrm{g} \mathrm{planta}^{-1} \mathrm{e}$ $0,93 \mathrm{~g} \mathrm{planta}^{-1}$, respectivamente. É importante destacar que ambos os autores utilizaram areia lavada como substrato, contida em sacos para mudas com capacidade para 3 litros, com regas efetuadas com solução nutritiva contendo macronutrientes e micronutrientes.

A dose de $210 \mathrm{~kg} \mathrm{ha}^{-1}$ de $\mathrm{N}$ resultou em maiores valores para todas as características agronômicas avaliadas, exceto diâmetro de caule, o que é positivo para sua aceitação no mercado de hortaliças (Tabela 1). Segundo Gallacher (1999), um produto de qualidade elevada tem diâmetro de caule entre $15 \mathrm{~mm}$ e $25 \mathrm{~mm}$. Os resultados obtidos no presente trabalho mostram que, com aplicações de nitrogênio, todas as plantas ficaram incluídas dentro dessa amplitude.

$\mathrm{O}$ aumento de nitrogênio no solo, acima de $210 \mathrm{~kg} \mathrm{ha}^{-1}$, demonstrou efeito negativo sobre a produtividade da cultura, sendo registrados $20,6 \%$ de redução no número máximo de folhas, na dose de $420 \mathrm{~kg} \mathrm{ha}^{-1}$ de N. Os resultados mostram que a couve-da-Malásia respondeu significativamente à adubação nitrogenada, sendo a produção muito reduzida na ausência de nitrogênio, o que evidencia a importância deste nutriente para o desenvolvimento desta brássica.

\section{AGRADECIMENTOS}

Os autores agradecem à Kátia Aparecida de Sá e Aline Mariano Silva
Tabela 2. Teores de macronutrientes e micronutrientes na parte aérea dae couve da Malásia, em função de diferentes doses de nitrogênio. Uberlândia, UFU, 2003.

\begin{tabular}{|c|c|c|c|c|c|c|}
\hline \multirow{2}{*}{$N\left(k g h a^{-1}\right)$} & $\mathbf{N}$ & $\mathbf{P}$ & $K$ & $\mathrm{Ca}$ & $\mathrm{Mg}$ & $S$ \\
\hline & \multicolumn{6}{|c|}{$\mathrm{g} \mathrm{kg}^{-1}$} \\
\hline 0 & 12,73 & 4,20 & 34,75 & 17,40 & 2,48 & 5,65 \\
\hline 105 & 23,98 & 3,33 & 35,13 & 25,58 & 3,05 & 6,38 \\
\hline 210 & 25,72 & 2,68 & 31,20 & 21,93 & 2,63 & 5,73 \\
\hline 315 & 31,23 & 2,38 & 31,13 & 21,38 & 2,53 & 5,73 \\
\hline 420 & 32,90 & 2,10 & 31,13 & 21,28 & 2,48 & 5,60 \\
\hline \multirow{2}{*}{$N\left(k^{\prime} a^{-1}\right)$} & B & & & & $M n$ & $\mathrm{Zn}$ \\
\hline & \multicolumn{6}{|c|}{$\mathrm{mg} \mathrm{kg}^{-1}$} \\
\hline 0 & 164,5 & & & & 82,50 & 38,00 \\
\hline 105 & 145,3 & & & & 214,50 & 45,25 \\
\hline 210 & 106,5 & & & & 214,25 & 49,12 \\
\hline 315 & 98,0 & & & & 188,75 & 50,50 \\
\hline 420 & 78,0 & & & & 172,25 & 54,25 \\
\hline
\end{tabular}

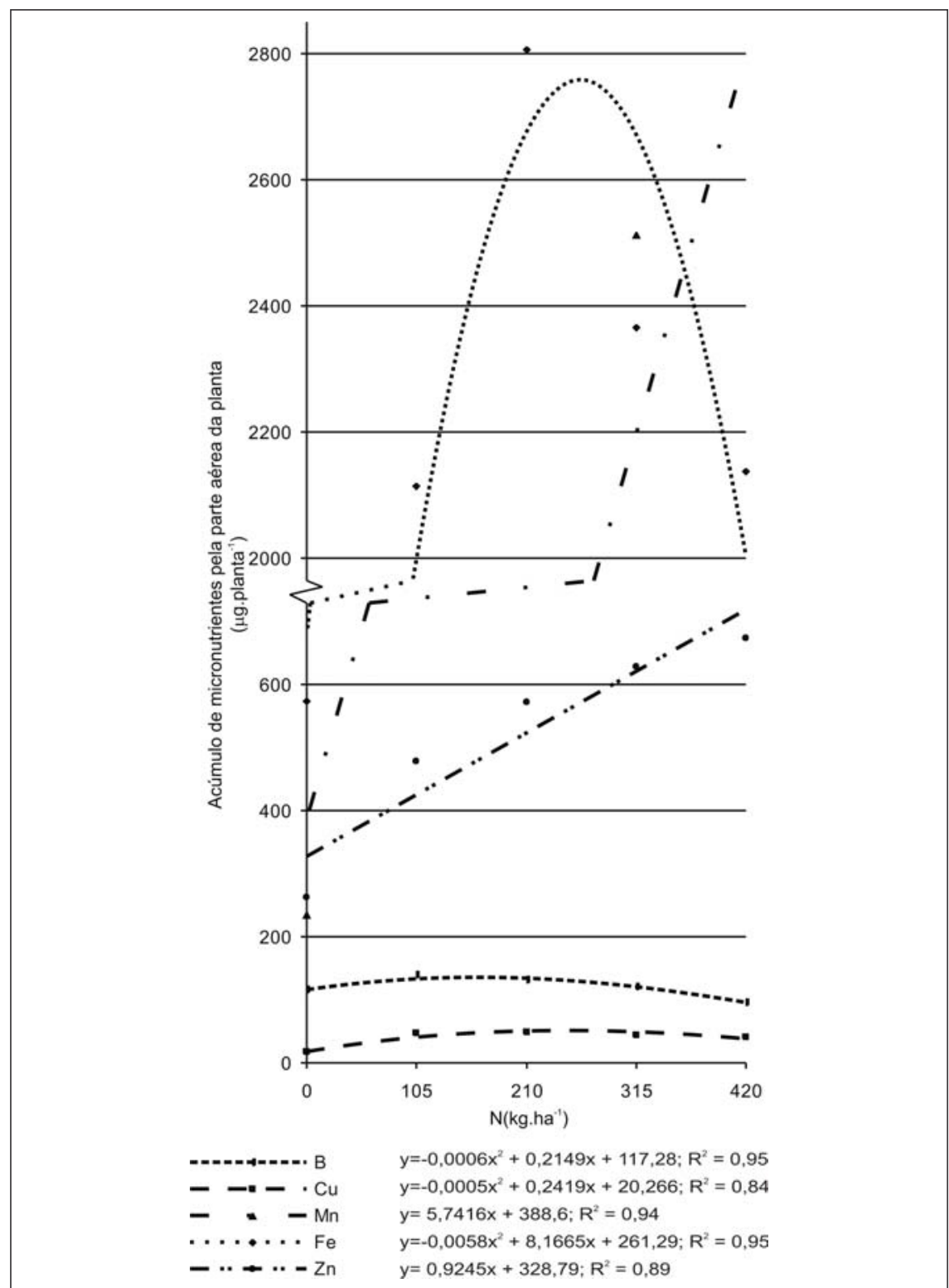

Figura 2. Acúmulo de micronutrientes (B, Cu, Mn, Fe e $\mathrm{Zn})$ pela parte aérea da couve-daMalásia, em função de doses de nitrogênio. Uberlândia, UFU, 2003. 
pelo apoio técnico, à Dra. Denise Garcia de Santana pelas sugestões na análise estatística dos dados, ao Sr. John David Bagnall pela revisão do abstract e aos anônimos revisores pelas sugestões e críticas construtivas.

\section{LITERATURA CITADA}

BAILEY, L.H. The cultivated brassicas. Gentes Herbarum, v.2, n.5, p.209-267, 1930.

BATAGLIA, O.C.; FURLANI, A.M.C.; TEIXEIRA, J.P.F.; FURLANI, P.R.; GALLO, J.R Métodos de análise química de plantas. Campinas: Instituto Agronômico, 1985. 48 p. (Boletim Técnico, 78).

CASTELLANE, P.D.; SOUZA, A.F.; MESQUITA FILHO, M.V. Culturas olerícolas. In FERREIRA, M.E.; CRUZ, M.C.P. (Ed.) Micronutrientes na agricultura. Piracicaba: Associação Brasileira para Pesquisa da Potassa e do Fosfato, 1991. p.549-584.

DANTAS, B.F. Efeito do metanol na produtividade de couve-da-Malásia (Brassica chinensis var parachinensis (Bailey) Sinskaja). 1997. $43 \mathrm{f}$ (Monografia graduação) - UFU, Uberlândia. FERREIRA, M.E.; CRUZ, M.C.P. Micronutrientes no solo. In: FERREIRA, M.E.; CRUZ, M.C.P (Ed.) Micronutrientes na agricultura. Piracicaba: POTAFOS/CNPq, 1991. p.131-157.

FERREIRA, W.R.; RANAL, M.A. Germinação de sementes e crescimento de plântulas de Brassica chinensis L. var. parachinensis (Bailey) Sinskaja (couve-da-Malásia). Pesquisa Agropecuária Brasileira, Brasília, v.34, n.3, p.353361, 1999.
FERREIRA, W.R.; RANAL, M.A.; FILGUEIRA, F.A.R. Fertilizantes e espaçamento entre plantas na produtividade da couve-da-Malásia. Horticultura Brasileira, Brasília, v.20, n.4, p.635640, 2002.

FURLANI, A.C.M.; FURLANI, P.R.; BATAGLIA, O.C. Composição mineral de diversas hortaliças. Bragantia, Campinas, v.37, p.3344, 1978.

GALLACHER, D. Chinese flowering cabbage. Queensland, mai. 1999. Disponível em <http:// www.ahs.cqu.edu.au/info/science/psg/AsianVeg/ ChinFlCabb.html> Acesso em: 20 out. 2003.

HERKLOTS, G.A.C. Vegetable in south-East Asia. Hong Kong: George Allen \& Unewin Ltda, 1972. $525 \mathrm{p}$.

HILL, T.R. The effect of nitrogenous fertilizer and plant spacing on the yield of three Chinese vegetables - Kai lan, Tsoi sum and Pak choi. Scientia Horticulturae, v.45, p.11-20, 1990.

KIMOTO, T. Nutrição e adubação de repolho, couve-flor e brócolo. In: FERREIRA, M.E.; CASTELLANE, P.D.; CRUZ, M.C.P. (Eds.). $N u$ trição e adubação de hortaliças. Piracicaba: Associação Brasileira para Pesquisa da Potassa e do Fosfato, 1993. p.149-178.

LEE, S.H. Vegetable crops growing in China. Scientia Horticulturae, v.17, p.201-209, 1982.

MORAGHAN, J.T.; MASCAGNI JR., H.J. Environmental and soil factors affecting micronutrient deficiencies and toxicities. In: MORTVEDT, J.J.; COX, F.R.; SHUMAN, L.M.; WELCH, R.M. (Ed.) Micronutrients in agriculture. 2.ed. Madison: SSSA, 1991. p.371-425.

MOTA, G.M.F. Cultivo de Brassica chinensis var. parachinensis (Bailey) Sinskaja na ausência de micronutrientes. 2001. 36 f. (Monografia graduação) - UFU, Uberlândia.
OPEÑA, R.T.; KUO, C.G.; YOON, J.Y. Breeding and seed production of Chinese cabbage in the Tropics and Subtropics. Tainan, Taiwan: Asian Vegetable Research and Development Center, 1988. 92 p. (Technical Bulletin, 17).

RIBEIRO, A.C.; GUIMARÃES, P.T.G.; ALVAREZ V.,V.H. Recomendações para o uso de corretivos efertilizantes em Minas Gerais: $5^{a}$ aproximação. Comissão de Fertilidade do Solo do Estado de Minas Gerais. Viçosa: UFV, 1999. 359 p. SILVA, F.C.; EIRA, P.A.; VAN RAIJ, B.; SILVA, C.A.; ABREU, C.A.; GIANELLO, C.; PÉREZ, D.V.; QUAGGIO, J.A.; TEDESCO, M.J.; ABREU, M.F.; BARRETO, W.O. Análises químicas para avaliação da fertilidade do solo. In: SILVA, F.C. (Ed.) Manual de análises químicas de solos, plantas e fertilizantes. Brasília: Embrapa Comunicação para Transferência de Tecnologia, 1999. p.75-169.

SOUSA, E.R. Efeito da nutrição mineral na produtividade de couve-da-Malásia (Brassica chinensis var parachinensis (Bailey) Sinskaja). 1997. 29 f. (Monografia graduação) - UFU, Uberlândia.

TRANI, P.E.; GRANJA, N.P.; BASSO, L.C.; DIAS, D.C.F.S.; MINAMI, K. Produção e acúmulo de nitrato pela rúcula afetados por doses de nitrogênio, Horticultura Brasileira, Brasília, v.12, n.1, p.25-29, 1994.

YIP, S.M.; PAO, C.S.; TONG, T.C.; NG, Y.S. A note on some studies of chinese flowering cabbage (Brassica parachinensis Bailey). Agric. HongKong, v.1, n.5, p.407-418, 1976. 